\title{
Correlates of Unintended Pregnancies in Ivory Coast: Results from a National Survey
}

\author{
Kpebo Djoukou Olga Denise ${ }^{1,2}$, Aké-Tano Sassor Odile Purifine ${ }^{1,2}$, Aka Joseph ${ }^{1,2}$, \\ Konan Yao Eugène ${ }^{1,2}$, Attoh-Touré Harvey ${ }^{2,3}$, Tetchi Ekissi Orsot ${ }^{1,2}$, Dagnan N'Cho Simplice ${ }^{2,3}$ \\ ${ }^{1}$ National Institute of Public Health, Abidjan, Ivory Coast \\ ${ }^{2}$ Public Health and Biostatistics Department, Medical School, University Félix Houphouet Boigny, Abidjan, Ivory Coast \\ ${ }^{5}$ National Institute of Public Hygiene, Abidjan, Ivory Coast
}

Email address:

dkpebo@gmail.com (K. D. O. Denise)

${ }^{*}$ Corresponding author

\section{To cite this article:}

Kpebo Djoukou Olga Denise, Aké-Tano Sassor Odile Purifine, Aka Joseph, Konan Yao Eugène, Attoh-Touré Harvey, Tetchi Ekissi Orsot, Dagnan N'Cho Simplice. Correlates of Unintended Pregnancies in Ivory Coast: Results from a National Survey. Science Journal of Public Health. Vol. 6, No. 1, 2018, pp. 6-14. doi: 10.11648/j.sjph.20180601.12

Received: September 27, 2017; Accepted: October 19, 2017; Published: December 5, 2017

\begin{abstract}
As in most of Africa, unintended pregnancy remains a major reproductive health challenge in Ivory Coast. The 3 Demographic and Health Survey (DHS) conducted in the country in 1994, 1999, and 2012, revealed a decreasing trend in the percentage of unwanted pregnancies: 7.8\%, 4.9\%, 3.3\% in 1994, 1999, and 2012 respectively. However, the percentage of births that were wanted later remained regularly high, around $20 \%$ with a pic on $23.8 \%$ in 1999 . Understanding the extent of unintended pregnancy and the factors associated is crucial to conduct evidence-based interventions and avoiding women's resort to unsafe abortions. A secondary analysis of the DHS 2011-2012 of Ivory Coast allowed to include 1032 pregnant women at the time of data collection. A bivariate analysis and multivariate was conducted with Stata 14.0 for identifying associated factors with unintended pregnancy. In total, $26.4 \%$ of the pregnancies were unintended. Age was not found as a correlate of unintended pregnancy. Women in primary and secondary education categories were more likely to have unintended pregnancy as compared to the no education category (OR (95\% CI): 2.0 (1.3-3.1) and 2.1 (1.1-4.0) respectively). Ever use of family planning, high parity ( 5 children and more), and one as well as two and more deliveries in the past five years were associated with unintended pregnancy (OR (95\%CI): 2.1 (1.4-3.2), 3.5 (1.2-10.2) and 2.8 (1.5-5.5), respectively). Partner's desire for less children was also found to be associated with unintended pregnancy (OR $(95 \% \mathrm{CI})$ : 1.9 (1.1-3.1)). Women already burdened with higher fertility were suffering from unintended pregnancy. Efforts to increase the use of family planning services among these women should be strengthened.
\end{abstract}

Keywords: Unintended Pregnancies, Family Planning, Associated Factors, Ivory Coast

\section{Introduction}

Unintended pregnancies refer to pregnancies that are reported to have been either unwanted (not wanted at the time) or mistimed (wanted but at a later time) [1, 2]. Globally, it is estimated that there are 87 million cases of unintended pregnancies annually of which 46 million cases resort to induced abortion, including 18 million of unsafe abortions [2, 3]. In sub-Saharan Africa, unintended pregnancy accounts for more than a quarter of the 40 million pregnancies that occur annually $[4,5,6]$.
There are a number of factors predicting the occurrence of unintended pregnancies. The socio-demographics factors that were reported to have been associated with increased level of unintended pregnancies included younger age, less level of education, unmarried, rural residence, and lower income $[7,8$, and 9]. Besides these demographics factors, failure of the healthcare system to meet the demands for reproductive health services particularly that limit size is also recognized as another major cause [10]. In addition, partner desire for 
child, domestic violence and less autonomy are also correlates of unintended pregnancies $[8,9]$.

Unintended pregnancies have been a major public health issue due to its adverse consequences to the maternal and child health $[10,11]$. It is a major cause of unsafe abortion and related maternal deaths, low birth weight baby, preterm birth, and high infant mortality [3, 5, 12, 13, 14].

As in most of Africa, unintended pregnancy remains a major reproductive health challenge in Ivory Coast. The 3 Demographic and Health Survey (DHS) conducted in the country in 1994, 1999, and 2012, revealed a decreasing trend in the percentage of unwanted pregnancies: $7.8 \%, 4.9 \%, 3.3 \%$ in 1994, 1999, and 2012 respectively. However, the percentage of births that were wanted later remained regularly high, around $20 \%$ with a pic on $23.8 \%$ in 1999 [15]. Like other developing countries, the majority of these unintended pregnancies will end up with induced abortion, mostly unsafe abortion [16]. A national survey conducted in 2007 among 1549 years old women, estimated a high prevalence of unsafe abortion, up to $42.7 \%$ putting these women at a high risk of dying from the complication of unsafe abortion [17].

Understanding the extent of unintended pregnancy and the factors associated is crucial to conduct evidence-based interventions and avoiding women's resort to unsafe abortions. Even though researches from other countries presented a detailed report on the issue, in Ivory Coast, available literature do not provide sufficient evidence and national as well as subnational level information are lacking; as a result, statistics regarding this phenomenon is hardly available. In order to fill this gap in, this report based on analysis of existing data from the Ivorian Demographic and Health Survey (IDHS) 2011-2012, aimed at assessing the prevalence of and factors associated with unintended pregnancies to avail evidence for future decision-making.

\section{Methodology}

\subsection{Source of Data and Sample Size}

The data for this paper were drawn from the 2011-2012 IDHS. It is part of a worldwide MEASURE DHS project funded by the United States Agency for International Development (USAID) and implemented by the Ivorian National Statistical Agency. It is a community based analytical cross sectional study that is undertaken every 5 years and the 2011 survey is the third DHS in Ivory Coast. The first DHS was performed in 1994 and the second in 1999 [10].

Ivory Coast is divided into 11 study sites, the 10 former administrative regions and the city of Abidjan, and all of them were covered by this third IDHS. Information were collected from a nationally representative sample of 10,413 households, 10,848 women (15-49 years), 5,677 men (15-49 years) [DHS Ivory Coast]. A stratified, two stage cluster sampling procedure was used to identify the representative samples. The sampling frame consists of strata or
Enumeration Areas (EAs). An EA is a geographic area consisting of a convenient number of dwelling units. On the first stage, 352 EAs were selected, 16 in urban areas and 191 in rural areas using probability to proportional size method. Then, on second stage, based on the place of residence, a fixed number of households per EA was 27 in urban area and 32 in rural area [10].

The 2011 IDHS used questionnaires that were adapted from model survey instruments developed for the MEASURE DHS project, to which were added some modules developed by UNICEF for the Multiple Indicators Clustered Survey (MICS). Various Stakeholders (Experts from the government and the partner institutions) were consulted to improve on the tools considering both users' need and key issues in the field of population and health [10].

Prior to start of fieldwork, the survey tools were pre-tested on 4 sites to make sure questions were clear and understandable to the respondents. The questionnaires were modified following the input of the pre-test, then a 2 weeks training was conducted for the interviewers, editors and supervisors, for collecting data related to: family planning; fertility levels and determinants; fertility preferences; infant, child, adult and maternal mortality; maternal and child health; nutrition; women's empowerment and knowledge of HIV/AIDS. It also collected information on unintended pregnancy and only women who were pregnant at the time of data collection were included in the analysis. In fact, retrospectively reported pregnancy intentions for past pregnancies generally become more positive as mothers tend to like the baby once born [18]. Hence the analysis was made only the sub-sample of 1032 women who were pregnant at the time of data collection.

\subsection{Study Variables}

\subsubsection{Outcome Measure}

Women were asked if the current pregnancy was wanted or not. If the pregnancy was wanted then, it is considered to be planned. It is considered to be mistimed if it was wanted but at a later time; and unwanted if it was not wanted at the time. Mistimed and unwanted pregnancies were merged as "unintended" to create a binary variable with the planned pregnancies (intended).

\subsubsection{Exposure Measures}

The potential predictors of unintended pregnancy identified in the dataset were grouped into sociodemographic, reproductive and autonomy related variables.

a) Socio-demographic characteristics of women: age, residence, (Urban/Rural), education, marital status, wealth Index.

b) Reproductive Health: ideal number of children, number of children ever born, number of living children, entry birth order, number of births in the past five years, ever terminated pregnancy, knowledge of ovulation timing, ever use of family planning, partner desire for children.

c) Autonomy is represented by selected direct measures of 
women's autonomy [10]: decision-making power on woman's visit to families or relatives, decision-making power on making large household purchases, decision making on women's health care, and women's attitude toward wife beating. The response categories for decisionmaking variables are "respondent alone", "jointly with partner", and "partner/someone else".

\subsection{Data Analysis}

Percentage and mean/median were used to describe the socio-demographic and reproductive characteristics of study participants. Bivariate analysis in terms of Chi-square test has been used to assess the effect of each independent variable towards unintended pregnancy. Ideal number of children ever born, number of living children and entry birth order demonstrated correlation. To avoid multicollinearity, only "number of children ever born" was selected to be included in the logistic regression analysis. Independent variables with p-value less than 0.25 in the bivariate analysis were included in the multiple logistic regression analysis to control for possible confounding factors [19]. Multiple logistic regression analysis was used, and Odds Ration with 95\% Confidence Interval (95\% CI) computed to describe the association of risk factors with unintended pregnancy. Statistical significance was considered at p-value less than 0.05 . Stata 14.0 software was used in the analysis of data.

\subsection{Ethical Review}

Ethical clearance for the survey was provided by the Ivorian National Research and Ethics Committee and Institutional Review Board of ICF International, and the Center for Disease Control [10]. Detailed information on the study area, study population, organization of the survey, sample design, questionnaires, data collection, data quality, data processing and ethical issue is published in the Ivorian Demographic and Health Survey 2011 report [10]. The primary author communicated with MEASURE DHS/ICF International and permission was granted to download and use the data for this project.

\section{Results}

\subsection{Sociodemographic Characteristics of Respondents}

Table 1 summarizes the socio-demographic characteristics of study participants. In order to ensure representativeness across the country, data was weighted according to survey sample A total of 1032 currently pregnant women in the 2011 IDHS were included in the analysis. More than 2-third of the respondents were between 20 and 34 years of age with overall mean age of 26.7 (+/-6.59). The majority of women were rural residents and married. About 2-third never had formal education while nearly half of them belonged to the poor wealth index categories.

Table 1. Sociodemographic characteristics of pregnant study participants, Ivory Coast.

\begin{tabular}{lll}
\hline Sociodemographic characteristics & Frequency & Percentage \\
\hline Age (years) & & \\
$15-19$ & 177 & 17.2 \\
$20-24$ & 251 & 24.3 \\
$25-29$ & 256 & 24.8 \\
$30-34$ & 205 & 19.9 \\
$35-39$ & 110 & 10.7 \\
$40-44$ & 24 & 2.4 \\
$45-49$ & 09 & 0.7 \\
Mean (SD) & $26.7(6.59)$ & \\
Type of Place of Residence & & \\
Urban & 431 & 41.7 \\
Rural & 601 & 58.3 \\
Current Marital Status & & \\
Never in union & 145 & 14.1 \\
Married & 503 & 48.8 \\
Living with partner & 358 & 34.7 \\
Widowed & 05 & 0.4 \\
Divorced & 05 & 0.4 \\
No longer living together/separated & 16 & 1.5 \\
Highest Education level & & \\
No education & 612 & 59.3 \\
Primary & 257 & 24.9 \\
Secondary & 140 & 13.5 \\
Higher & 23 & 2.2 \\
Wealth Index & & \\
Poorest & 219 & 21.2 \\
Poorer & 243 & 23.5 \\
Middle & 202 & 19.6 \\
Richer & 197 & 19.1 \\
Richest & 171 & 16.6 \\
\hline
\end{tabular}

\subsection{Reproductive Health Characteristics}

Nearly three-fourth of the respondents reported that the current pregnancy is wanted at that point while those who wanted it at a later time and not at all accounted for $23.1 \%$ and $3.3 \%$ respectively. The unintended pregnancy rate ranged from $12.8 \%$ in the Northern region to more than $35 \%$ in the Central, the East Central regions and in Abidjan, the economic capital of the Country. The number of children ever born ranged from $0(24.4 \%)$ to 5 children and more $(16.5 \%)$. Slightly more than $40 \%$ of the respondents had no birth in the last five years preceding the survey. About one-third of the women reported their desired number of children to be 6 or more. Respondents who knew of modern contraceptives represented $93.4 \%$ of respondents while $27.9 \%$ recognized that ovulation time is at the middle of the cycle. Ever use of family planning method was reported by $66.9 \%$ of the respondents. Nearly one-third of the respondents reported that both partners desire the same number of children whereas one-fifth stated that the partner wants more number of children (Table 2 and Table 3 ). 
Table 2. The Prevalence of Unintended Pregnancy in the 11 Regions of Ivory Coast, 2011.

\begin{tabular}{lll}
\hline Regions & Unintended (\%) & Intended (\%) \\
\hline Centre & $29(35.6)$ & $53(64.6)$ \\
East Centre & $26(37.7)$ & $43(62.3)$ \\
North Centre & $25(24.7)$ & $76(75.3)$ \\
West Centre & $18(18.7)$ & $78(81.3)$ \\
North & $10(12.8)$ & $68(87.2)$ \\
North East & $18(22.8)$ & $61(77.2)$ \\
North West & $27(20.2)$ & $107(79.8)$ \\
West & $29(29.9)$ & $68(70.1)$ \\
South without Abidjan & $22(28.9)$ & $54(71.1)$ \\
South West & $26(24.5)$ & $80(75.5)$ \\
Abidjan & $35(35.7)$ & $63(64.3)$ \\
Total & $265(26.1)$ & $751(73.9)$ \\
\hline
\end{tabular}

Table 3. Reproductive characteristics of pregnant study participants, Ivory Coast, 2011.

\begin{tabular}{|c|c|c|}
\hline Characteristics & Frequency & Percentage \\
\hline \multicolumn{3}{|l|}{ Current pregnancy wanted } \\
\hline Then & 754 & 73.7 \\
\hline Later & 236 & 23.1 \\
\hline Not at all & 34 & 3.3 \\
\hline \multicolumn{3}{|l|}{ Number of children ever born } \\
\hline 0 & 252 & 24.4 \\
\hline $1-2$ & 385 & 37.3 \\
\hline $3-4$ & 225 & 21.8 \\
\hline $5+$ & 170 & 16.5 \\
\hline Median (IQR) & $2(3)$ & \\
\hline \multicolumn{3}{|l|}{ Births in the last 5 years } \\
\hline No births & 414 & 40.1 \\
\hline 1 & 453 & 43.9 \\
\hline 2 & 156 & 15.1 \\
\hline 3 & 09 & 0.8 \\
\hline Median (IQR) & $1(1)$ & \\
\hline \multicolumn{3}{|l|}{ Ideal number of children } \\
\hline 0 & 06 & 0.6 \\
\hline 1 & 03 & 0.3 \\
\hline 2 & 24 & 2.4 \\
\hline 3 & 79 & 7.6 \\
\hline 4 & 230 & 22.3 \\
\hline 5 & 245 & 23.8 \\
\hline $6+$ & 350 & 34.0 \\
\hline Non numeric answers & 94 & 9.1 \\
\hline \multicolumn{3}{|l|}{ Knowledge of any methods } \\
\hline Knows no methods & 65 & 6.3 \\
\hline Knows only traditional method & 03 & 0.2 \\
\hline Knows modern method & 964 & 93.4 \\
\hline \multicolumn{3}{|l|}{ Ever used Family Planning Method } \\
\hline Yes & 690 & 66.9 \\
\hline No & 342 & 33.1 \\
\hline \multicolumn{3}{|l|}{ Knows the timing of ovulation } \\
\hline Yes & 288 & 27.9 \\
\hline No & 744 & 72.1 \\
\hline \multicolumn{3}{|l|}{ Partner's desire for children } \\
\hline Bothwant the same & 228 & 26.6 \\
\hline Husbandwants more & 180 & 20.9 \\
\hline Husband wants fewer & 49 & 5.7 \\
\hline Don’t know & 402 & 46.8 \\
\hline \multicolumn{3}{|c|}{ Person who usually decides on respondent's health care } \\
\hline Respondent alone & 60 & 7.1 \\
\hline Respondent and husband/partner & 209 & 24.4 \\
\hline Husband/partner alone & 576 & 67.2 \\
\hline Someone else & 06 & 0.7 \\
\hline Other & 05 & 0.6 \\
\hline \multicolumn{3}{|c|}{ Person who usually decides on large household purchases } \\
\hline Respondent alone & 60 & 7.0 \\
\hline Respondent and husband/partner & 245 & 28.6 \\
\hline Husband/partner alone & 543 & 63.4 \\
\hline
\end{tabular}




\begin{tabular}{llc}
\hline Characteristics & Frequency & Percentage \\
\hline Someone else & 06 & 0.7 \\
Other & 03 & 0.3 \\
Person who usually decides on visits to family or relatives & & 14.2 \\
Respondent alone & 122 & 28.2 \\
Respondent and husband/partner & 242 & 55.9 \\
Husband/partner alone & 480 & 1.1 \\
Someone else & 09 & 0.6 \\
Other & 05 & 51.7 \\
Wife beating justifiable & & 48.3 \\
Yes & 533 & 499 \\
No & 499 & \\
\hline
\end{tabular}

\subsection{Bivariate Analysis of Exposure Measures}

Table 4 and 5 describe the bi-variate analysis result between the exposure measures and the outcome measures (unintended pregnancy). Age, current marital status and level of education were among the socio-demographic variables that showed significant association with unintended pregnancy $(\mathrm{p}<0.05)$. Among the reproductive characteristics, the variables that demonstrated significant relationship with unintended pregnancy included number of children ever born, ideal number of children and ever use of family planning $(\mathrm{p}<0.05)$. With regards to decision-making power, both decision-making on respondent's visit to family and decision making on respondent's healthcare showed statistically significant association in the bi-variate analysis $(\mathrm{p}<0.05)$.

Table 4. Bivariate analysis of socio-demographic and reproductive characteristics versus unintended pregnancy, Ivory Coast, 2011.

\begin{tabular}{|c|c|c|c|}
\hline & \multicolumn{2}{|c|}{ Unintended Pregnancy } & \multirow{3}{*}{ Chi-Square p-value } \\
\hline & \multicolumn{2}{|c|}{ Number (Row\%) } & \\
\hline & Yes & No & \\
\hline \multicolumn{4}{|l|}{ Characteristics } \\
\hline \multicolumn{4}{|l|}{ Age (Years) } \\
\hline $15-19$ & $61(34.4)$ & $116(65.6)$ & \multirow{5}{*}{$15.9(0.05)$} \\
\hline $20-24$ & $74(29.4)$ & $117(70.6)$ & \\
\hline $25-29$ & $65(25.3)$ & $191(74.7)$ & \\
\hline $30-34$ & $36(17.4)$ & $169(82.6)$ & \\
\hline $35-49$ & $34(24.0)$ & $108(76.0)$ & \\
\hline \multicolumn{4}{|l|}{ Type of place of residence } \\
\hline Urban & $116(26.9)$ & $315(73.1)$ & \multirow{2}{*}{$0.24(0.72)$} \\
\hline Rural & $157(25.6)$ & $444(74.4)$ & \\
\hline \multicolumn{4}{|l|}{ Current marital status } \\
\hline Not in Union & $96(56.3)$ & $75(43.7)$ & \multirow{3}{*}{$95.1(<0.0000)$} \\
\hline Married & $105(20.8)$ & $398(79.2)$ & \\
\hline Living with partner & $69(19.3)$ & $289(80.7)$ & \\
\hline \multicolumn{4}{|l|}{ Highest Educational Level } \\
\hline No education & $121(19.7)$ & $491(80.3)$ & \multirow{3}{*}{$33.0(<0.0004)$} \\
\hline Primary & $86(33.4)$ & $171(66.6)$ & \\
\hline Secondary & $63(38.8)$ & $100(61.2)$ & \\
\hline \multicolumn{4}{|l|}{ Wealth index } \\
\hline Poorest & $44(20.2)$ & $175(79.8)$ & \multirow{5}{*}{$9.9(0.16)$} \\
\hline Poorer & $67(27.5)$ & $176(72.5)$ & \\
\hline Middle & $61(30.4)$ & $141(69.6)$ & \\
\hline Richer & $44(22.1)$ & $153(77.9)$ & \\
\hline Richest & $54(31.3)$ & $117(68.7)$ & \\
\hline \multicolumn{4}{|c|}{ Number of children ever born } \\
\hline 0 & $92(36.6)$ & $160(63.4)$ & \multirow{4}{*}{$22.4(<0.005)$} \\
\hline $1-2$ & $83(21.6)$ & $302(78.4)$ & \\
\hline $3-4$ & $46(20.4)$ & $179(79.6)$ & \\
\hline $5+$ & $48(28.4)$ & $122(71.6)$ & \\
\hline \multicolumn{4}{|l|}{ Births in the last 5 years } \\
\hline No births & $109(26.2)$ & $306(73.8)$ & \multirow{3}{*}{$9.8(0.07)$} \\
\hline 1 & $103(22.7)$ & $350(77.3)$ & \\
\hline $2+$ & $59(35.4)$ & $106(64.5)$ & \\
\hline \multicolumn{4}{|l|}{ Ideal number of children } \\
\hline 3 or less & $50(45.5)$ & $44(54.5)$ & \multirow{5}{*}{$48.2(<0.000)$} \\
\hline 4 & $83(36.0)$ & $147(64.0)$ & \\
\hline 5 & $51(20.9)$ & $194(79.1)$ & \\
\hline $6+$ & $67(22.6)$ & $284(77.4)$ & \\
\hline Non-numeric answers & $17(18.7)$ & $76(81.3)$ & \\
\hline \multicolumn{4}{|l|}{ Knowledge of any methods } \\
\hline Knows no method & $11(21.6)$ & $58(78.4)$ & \multirow{2}{*}{$4.4(0.27)$} \\
\hline Knows modern method & $259(35.4)$ & $704(64.6)$ & \\
\hline
\end{tabular}




\begin{tabular}{|c|c|c|c|}
\hline & \multicolumn{2}{|c|}{ Unintended Pregnancy } & \multirow{3}{*}{ Chi-Square p-value } \\
\hline & \multicolumn{2}{|c|}{ Number (Row\%) } & \\
\hline & Yes & No & \\
\hline Ever used family planning methods & & & \\
\hline $\begin{array}{l}\text { Yes } \\
\text { No }\end{array}$ & $\begin{array}{l}244(35.4) \\
74(21.6)\end{array}$ & $\begin{array}{l}446(64.6) \\
268(78.4)\end{array}$ & $22.2(0.002)$ \\
\hline Knows the timing of ovulation & & & \\
\hline $\begin{array}{l}\text { Yes } \\
\text { No }\end{array}$ & $\begin{array}{l}83(29.9) \\
186(25.8)\end{array}$ & $\begin{array}{l}204(70.1) \\
558(74.2)\end{array}$ & $1.7(0.29)$ \\
\hline
\end{tabular}

Table 5. Bivariate analysis of partner's fertility desire and decision-making variables versus unintended pregnancy, Ivory Coast, 2011.

\begin{tabular}{|c|c|c|c|}
\hline & \multicolumn{2}{|c|}{ Unintended Pregnancy } & \multirow{3}{*}{ Chi-Square p-value } \\
\hline & \multicolumn{2}{|c|}{ Number (Row\%) } & \\
\hline & Yes & No & \\
\hline \multicolumn{4}{|l|}{ Characteristics } \\
\hline \multicolumn{4}{|l|}{ Partner's desire for children } \\
\hline Both want same & $40(17.7)$ & $188(82.3)$ & \multirow{2}{*}{8.2} \\
\hline Husband wants more & $42(23.4)$ & $138(76.6)$ & \\
\hline Husband wants fewer & $17(33.7)$ & $33(66.3)$ & $(0.2)$ \\
\hline \multicolumn{4}{|c|}{ Person who usually decides on the large household purchases } \\
\hline Respondent alone & $8(19.6)$ & $52(80.4)$ & \multirow{3}{*}{$\begin{array}{l}4.8 \\
(0.22)\end{array}$} \\
\hline Respondent and husband/partner & $31(15.3)$ & $178(84.7)$ & \\
\hline Husband/partner alone & $126(22.0)$ & $450(78.0)$ & \\
\hline \multicolumn{4}{|c|}{ Person who usually decides on respondent's health care } \\
\hline Respondent alone & $12(26.0)$ & $48(74.0)$ & \multirow{2}{*}{$\begin{array}{l}6.2 \\
(0.12)\end{array}$} \\
\hline Respondent and husband/partner & $37(13.8)$ & $208(86.2)$ & \\
\hline \multicolumn{4}{|c|}{ Person who usually decides on visits to family or relatives } \\
\hline Respondent alone & $32(26.0)$ & $91(74.0)$ & \multirow{3}{*}{$\begin{array}{l}8.4 \\
(0.05)\end{array}$} \\
\hline Respondent and husband/partner & $33(13.8)$ & $209(86.2)$ & \\
\hline Husband/partner alone & $98(20.3)$ & $383(79.7)$ & \\
\hline \multicolumn{4}{|l|}{ Wife beating justifiable } \\
\hline Yes & $138(25.9)$ & $395(74.1)$ & 0.01 \\
\hline No & $131(26.3)$ & $367(73.7)$ & $(0.92)$ \\
\hline
\end{tabular}

\subsection{Multiple Logistic Regression Analysis of Exposure Measures}

Table 6 presents the results of the multiple logistic regression analysis for the socio-demographic and fertility variables with p-value less than 0.25 in the bivariate analysis. Age was not found as a correlate of unintended pregnancy. Women in primary and secondary education categories were more likely to have unintended pregnancy as compared to the no education category (OR $(95 \% \mathrm{CI}): 2.0$ (1.3-3.1) and 2.1 (1.1-4.0) respectively). High parity (5 children and more), and one delivery as well as two or more deliveries in the past five years were associated with unintended pregnancy (OR (95\%CI): $3.5 \quad(1.2-10.2), \quad 2.8 \quad(1.5-5.5), \quad 4.1 \quad(1.9-8.9))$ respectively). In addition, Ever use of family planning were also showing an increased risk of unintended pregnancies (OR (95\%CI): 2.1 (1.4-3.2)).

Finally, women without any healthcare decision-making power were also more likely to experience some unintended pregnancy as compared to women who were making such decision with their husband (OR (95\% CI): 1.9 (1.1-3.1)).

Table 6. Factors predicting unintended pregnancy among pregnant women (Logistic regression analysis), Ivory Coast, 2011.

\begin{tabular}{lll}
\hline Characteristics & Adjusted Odds ratio (95\% CI) & p-value \\
\hline Age (years) & Reference & \\
$15-19$ & $0.7(0.3-1.4)$ & 0.3 \\
$20-24$ & $0.6(0.3-1.3)$ & 0.2 \\
$25-29$ & $0.4(0.2-1.5)$ & 0.08 \\
$30-34$ & $0.6(0.2-1.5)$ & 0.3 \\
$35-49$ & & \\
Highest Education level & Reference & 0.003 \\
No education & $2.0(1.3-3.1)$ & 0.04 \\
Primary & $2.1(1.1-4.0)$ & \\
Secondary and above & & \\
Number of children ever born & Reference & 0.4 \\
0 & $0.6(0.3-1.6)$ & 0.5 \\
$1-2$ & $0.7(0.2-2.1)$ & 0.03 \\
$3-4$ & $3.5(1.2-10.2)$ & \\
$5+$ & & \\
\hline
\end{tabular}




\begin{tabular}{lll}
\hline Characteristics & Adjusted Odds ratio (95\% CI) & p-value \\
\hline Births in the last 5 years & & \\
No births & Reference & 0.003 \\
1 & $2.8(1.5-5.5)$ & 0.000 \\
$2+$ & $4.1(1.9-8.9)$ & \\
Ever used Family planning methods & & \\
No & Reference & 0.000 \\
Yes & $2.1(1.4-3.2)$ & \\
Partner's desire for more children & & \\
Both want same & Reference & 0.1 \\
Husband wants more & $1.6(0.9-2.8)$ & 0.04 \\
Husband wants fewer & $1.9(1.1-3.1)$ & \\
Persons who ususally decide on respondent's healthcare & & \\
Respondent and husband/partner & Reference & 0.1 \\
Respondent alone & $1.8(0.7-2.3)$ & 0.08 \\
Partner alone & $2.1(0.3-3.1)$ & \\
\hline
\end{tabular}

\section{Discussion}

This study addressed the prevalence, socio-economics and demographic correlates of unintended pregnancy in Ivory Coast. Results showed that $26.4 \%$ of the pregnancies were unintended. The analysis was focused on the current pregnancy with the intention of minimizing both recall bias and underestimation of unintended pregnancy if one uses previous pregnancies [18].

The current rate is far more than the report of another national study conducted 10 years ago and which found a rate of $12 \%$ of unintended pregnancies among women aged 15-49 years who practiced abortion [17]. Although the study was concerned with abortion experiences, these results may reflect the underlying increase in the phenomenon of unintended pregnancy. In fact, abortion rates in Ivory Coast increased between 2002 and 2007 from $34 \%$ to $42 \%$; rates of unintended pregnancies may have similarly increased $[17,20,21]$.

The analysis revealed that some regional states have extremely low level of unintended pregnancy that resulted in the lowering of national average. The significant difference in the extent of unintended pregnancy between regions calls for the need of targeted interventions based on the enormity of the problem.

An unintended pregnancy rate of $26.4 \%$ at the national level indicates that, despite the progress observed, the nation is still struggling in terms of fulfilling one of the reproductive health rights, namely access to safe, effective, affordable, and acceptable methods of family planning. Contraceptive prevalence is still low, only $13.6 \%$ at the national level according to the last DHS survey [15].

It is one way of addressing the reproductive right of individuals and couples to access family planning services and hence minimize unintended pregnancies. If the women had had access to fertility control services, such huge number of unintended pregnancies wouldn't have occurred [2, 4, 22].

Both primary level and secondary and above level of education were shown to be associated with increased level of unintended pregnancy as compared to those women with no formal education. Better education was thought to reduce the chance of having unintended pregnancy which was not the case in the current analysis. Educational background has also been shown to have either insignificant or inconsistent relationship with unintended pregnancy in diverse settings $[2,25,26]$.

Despite high level of awareness (93.4\%), only 33.1\% of women had tried contraception at some point, showing a great gap between awareness and usage. The overall conclusion would be that knowledge does not seem to guarantee the practice of family planning [2, 25, 26]. Therefore, further research is necessary to study the possible factors that could affect this change. Possible factors that need to be investigated include fear of side effects, misinformation on contraception, spousal disapproval, adolescent discrimination in the use of contraception and fear of being wayward for using contraception among others [26, 27].

In addition, women who ever used any family planning were significantly more likely to report unintended pregnancy in conformity with study findings in Ethiopia, Bangladesh and Nigeria $[8,22,25]$. Women who ever used family planning might have utilized it long time ago and hence couldn't predict recent pregnancy outcome. It appears advisable to ask for a detailed information on ever use of family planning in terms of the timing. If the "ever use" is at a recent time, one can also think of contraception failure or discontinuation. The current dataset does not specify about the timing of past family planning use that would have helped to differentiate between recent and older exposure to family planning.

High parity (five or more children ever born) was significantly associated with unintended pregnancy. The expectation was that level of unintended pregnancy would be lower with increasing parity. The result indicating higher odds of unintended pregnancies with increasing parity among women is an observation which would need further investigation despite similar findings from other studies [23, 24].

Women with any history of pregnancies (one or two and more) in the five years preceding the survey were also more likely to have unintended pregnancies. It is an indication that there are women who continued living at risk of pregnancy despite attaining high level of fertility at one point in time. Different factors might have contributed for the failure of such 
women in avoiding unintended pregnancy. Such women with higher fertility are more likely to have unmet need for family planning. The factors predisposing the women to the risk of pregnancy might be related to the woman, partner, family, society, and health worker or health program performance [7, $8,9]$. In-depth investigation on such women in advised to assess the root cause of their failure that can help in developing evidence based intervention. Health programs have to devise a mechanism of reaching women with increased level of fertility who desire to space or limit birth.

Partner's desire for children was found to be associated with unintended pregnancy. Different studies revealed that partner's influence had a significant association with unintended pregnancy $[3,9,11]$.

The limitation of this study is that relevant variables such as cultural influence, accessibility to health service, communication between spouses, and reasons for the failure to avoid unintended pregnancy were not available in the dataset for analysis. Nevertheless, the strength of the DHS data lies on the representation of diverse population groups, wide geographic coverage, use of standard questionnaire and data processing.

\section{Conclusion}

A significant proportion of the current pregnancies were found to be unintended. Women already burdened with higher fertility were suffering from unintended pregnancy. Regional differences of unintended pregnancies were noted. Family planning programs need to target women with higher fertility to minimize the risk of unintended pregnancy. Reproductive Health managers are advised to investigate the effectiveness of the existing family planning program in reaching such groups of women. Targeted interventions need to be implemented in the regions with higher level of unintended pregnancy. Further in-depth investigation in recommended to identify the major gaps to be addressed in the prevention of unintended pregnancy.

\section{Acknowledgements}

1. The authors would like to acknowledge Measure DHS for allowing access to the 2011 DHS dataset for Ivory Coast. With regards to author's contribution, KDOD communicated with MEASURE DHS/ ICF International and permission was granted to download and use the data for this project. KDOD ASOP and AHJ conceptualized the paper, conducted data analysis and drafted the manuscript. KYE, AH, TEO and DNS commented and edited the drafts of the manuscript. All authors reviewed and approved the manuscript for submission.

\section{References}

[1] Santelli J, Rochat R, Hatfield-Timajchy K, Gilbert B, Curtis K Cabral R: The measurement and meaning of unintended pregnancy. Perspectives on Sexual and Reproductive Health 2003, 32 (2): 94-101.
[2] Singh S, Sedgh G, Hussain R (2010). Unintended pregnancy: worldwide levels, trends, and outcomes. Stud Fam Plann 41: 241-250. Doi: 10.1111/j.17284465.2010.00250.x.Pubmed: 21465725 .

[3] Kubicka L, Matejcek Z, David HP, Dytrych Z, Miller WB et al. (1995) Children from unwanted pregnancies in Prague, Czech Republic revisited at age thirty. ActapsychiatrScand 91: 361-369. Doi: 10.1111/j.

[4] Adetundji J: Levels, trends and determinants of unintended childbearing in developing countries. DHS Analytical Report No. 8. Calverton, Maryland: Macro International Inc.; 1998.

[5] Bitto A, Gray RH, Simpson JI, Queenan JT, Kambic RT, Perez A, Mena P, Barbato M, Li C, Jennings V: Adverse outcomes of planned and mistimed pregnancies among users of natural family planning: a prospective study. Am J Public Health 1997, 97 (3): 338-343.

[6] Forrest JD: Epidemiology of unintended pregnancy and contraceptive use. Am J Obstetrics Gynaecology 1994, 170 (5): $1485-1489$

[7] Bongaarts J: Trends in unwanted childbearing in the Developing world. Stud Fam Plan 1997, 28 (4): 267-277.

[8] Kamal M, Islam A (2011). Prevalence and socio-economic correlates of unintended pregnancy among women in rural Bangladesh. Salud Publica Mexico 53: 108-115. Doi: 10.1590/S0036-3642011000200003.

[9] Kaye DK, Mirembe FM, Bantebya G, Johansson A, Ekstrom AM (2006). Domestic violence as risk factor for unwanted pregnancy and induced abortion in Mulago Hospital, Kampala, Uganda. Trop Med Int Health 11 (1): 90-101. Pubmed 16398760.

[10] Rosenfield A: Prevention of maternal mortality Network. International Journal Gynecology Obstetrics 1997, 59:S1-S27.

[11] Tiwari A: The impact of psychological abuse by an intimate partner on mental health of pregnant women. BJOG, Blackwell Publishing 2008, 115: 377-384.

[12] Afable-Munsuz A, Braveman P: Pregnancy intention and preterm birth: differential associations among a diverse population of women. Perspect Sex Reprod Health 2008, 40 (2): 66-73.

[13] Exavery A, Kanté AM, Hingora A, Mbaraku G, Pemba S et al. (2013) How mistimed and unwanted pregnancies affect timing of antenatal care initiation in three districts in Tanzania. BMC Pregnancy Childbirth 13 (1): 35. doi: 10.1186/1471-2393-1335. PubMed: 23388110.

[14] Marston C, Cleland J (2003): Do unintended pregnancies carried to term lead to adverse outcomes for mother and child? An assessment in five developing countries. Popul Stud (Camb) 57 (1): 77-93. Doi: 10.1080/0032472032000061749. PubMed: 12745811.

[15] National Institute of Statistics (INS) and ICF International 2012. Demographic and Health Survey and Multiple Indicators Clustered Survey in Ivory Coast 2011-2012. Calverton, Maryland, USA: INS and ICF International.

[16] Grimes DA, Benson J, Singh S, Romero M, Ganatra B, et al. (2006) Unsafe abortion: The preventable pandemic. Lancet 368 (9,550): 1,908-1,919. 
[17] Benié BVJ, Tiembre I, Attoh H, Kouadio ED, Kouakou L, Coulibaly L, Kouakou A H, Saracino TJ: Epidemiology of induced abortion in Ivory Coast, Santé publique du 02/01/2012, volume 24, Avril-Mai, p. 67-76.

[18] African Population and Health Research Centre: Population and health dynamics in Nairobi informal settlements. Nairobi: African Population and Health Research Centre; 2002.

[19] Bowers D (2008) Medical statistics from scratch: an introduction for health professionals. John Wiley \& Sons.

[20] Desgrees DLA, Msellati P, Viho, Ekra WC: Resort to induced abortion in Abidjan: a cause of decreasing fecundity? Population 1999, vol 54 N³ Pp 427-446.

[21] Guillaume A, Desgrees DLA: Birth limitation among women in Abidjan, Ivory Coast, contraception, abortion or both? Family Planning Persp 2002; 28 (3): 159-66.

[22] Petersen R, Gazmararian JA, Anderson Clak K, Green DC: How contraceptive use patterns differ by pregnancy intention: implications for counseling. Women's Health Issues 2001, 11 (5): 427-435.
[23] Eliason S, Baiden F, Yankey BA, Awusabo-Asare K: Determinants of unintended pregnancies in rural Ghana. BMC Pregnancy and Childbirth 2014, 14: 261.

[24] Omane-Adjepong M, Oduro FT, Annin K: A multinomial regression analysis of unplanned pregnancies in AhafoAno South District, Ghana. Am Int J Contemp Res 2012, 2: 12.

[25] Adewole IF, Oye-Adeniran BA, Iwere N, Oladokun O, Gbadegesin A, Babarinsa AI. Contraceptive usage among abortion seekers in Nigeria. W Afr Med 2002; 21 (2): 112-4.

[26] Onuzurike BK, Usochukwu BSC. Knowledge, attitude and practice of family planning amongst women in high density low income urban of Enugu, Nigeria. Afr J Reprod Health 2001; 5 (2): 83-89.

[27] Aitken ME, Oconto PI, Andes BAA. Knowledge and perception of emergency contraception among female Nigerian undergraduates. Int Fam Plann Persp 2003; 29 (2): 84-87. 